\title{
The Influence of a Magnetic Storm on Tectonic Deformations and the Coast Effect
}

\author{
G. A. Sobolev* \\ Institute of Physics of the Earth, Russian Academy of Sciences, ul. Bol. Gruzinskaya, 10, str. 1, Moscow, 123242 Russia \\ *e-mail: sobolev@ifz.ru \\ Received October 20, 2020; revised December 3, 2020; accepted December 11, 2020
}

\begin{abstract}
Records of 58 identical broadband seismograph stations were studied made during strong geomagnetic storms. Oscillations of periods of a few hours were studied. These were compared with synchronous variations of earth tides. Anomalous changes in deformation rate were observed after storms at stations installed near continent-ocean boundaries. They lasted a few days and had amplitudes of a few millimeters per minute.
\end{abstract}

Key words: seismic stations, tectonic deformation, magnetic storm, earth tide, coast effect

DOI: $10.1134 / \mathrm{S} 0742046321020068$

\section{INTRODUCTION}

There are several publications, few so far, which are concerned with the influence of the Sun's electromagnetic radiation and magnetic storms on seismicity (Barsukov, 1991; Sobolev et al., 2001; Yesugey, 2009; Jeffrey and Jeremy, 2013; Trenkin, 2015). Zakrzhevskaya and Sobolev (2004) demonstrated that the rate of earthquakes with magnitudes equal to or greater than 3 increased during 2-7 days after storms in some regions of Central Asia, the Caucasus, and America. However, the effect has not been recorded in Alaska. There have also been studies of the influence of magnetic storms and of rapid changes in air pressure on seismic noise (Sobolev and Zakrzhevskaya, 2019; 2020). Sharp changes in the magnetic intensity components were virtually simultaneously accompanied by noise pulses at seismic stations in different regions of the world. The present study is concerned with noise during strong magnetic storms at periods of a few hours. We used records at IRIS broadband seismic stations (one sample per second) equipped with STS1 seismometers (Wieland and Streckeisen, 1982). Data for 58 stations that were continuously operated during some strong magnetic storms were retrieved from the GSNet_152.dat database. The stations are shown in a world map, Fig. 1. The LHZ channel of a station records the vertical velocity of ground motion; we will use a simpler term in what follows, viz., strain rate.

\section{THE METHOD}

The plot of $\mathrm{P}$ in Fig. 2a shows vertical tidal displacements of ground surface found for the coordinates of the PFO seismic station [33.60 N, 116.45 W] using the PETGTAB program (Wenzel, 1999) at a rate of one sample per minute. The plot of dP shows the time derivative, which is the rate of tidal variation at intervals of one minute. The plot of $\mathrm{dS}$ is the rate of strain as observed at the PFO station. The raw record (one sample per second) was averaged, sampled at one observation per $10 \mathrm{~s}$, and then microseisms at periods of a few seconds were filtered out using the Gauss filter (Hardle, 1989; Lyubushin, 2007)] with a radius of 30. Further, it was averaged and reduced to one-minute samples, and the sensitivity was diminished to make the range of $\mathrm{dS}$ equal to the variations in the rate of tidal change dP. In this way the range of oscillation at the axis of ordinates for $\mathrm{dS}$ was converted to arbitrary units, which can conveniently be used to find differences between the readings of the seismic channel and tide rate. It follows from comparison of the plots of dS and $\mathrm{dP}$ that the station clearly reproduces semidiurnal and diurnal variations in tidal rate. The correlation coefficient between $\mathrm{dS}$ and $\mathrm{dP}$ is 0.99 . The plot of dif gives the amplitude difference dif $=\mathrm{dS}-\mathrm{dP}$. The results of analogous calculations for the COR station [44.586 N, 123.303 W] are shown in Fig. 2b.

The amplitude of fluctuations in dif at different stations varied between 0.25 and $0.5 \mathrm{dP}$. An analysis of the shape of these variations suggests that these "residual" oscillations were due to different responses of seismic stations to tide-induced extension and compression phases. It is a well-known fact that the diagrams showing the behavior of solids under tension and compression are different (Malinin, 1975). The magnitude of "residual" oscillations depends on the inelastic properties of rocks beneath a station of interest, which is not taken into account in calculations of 


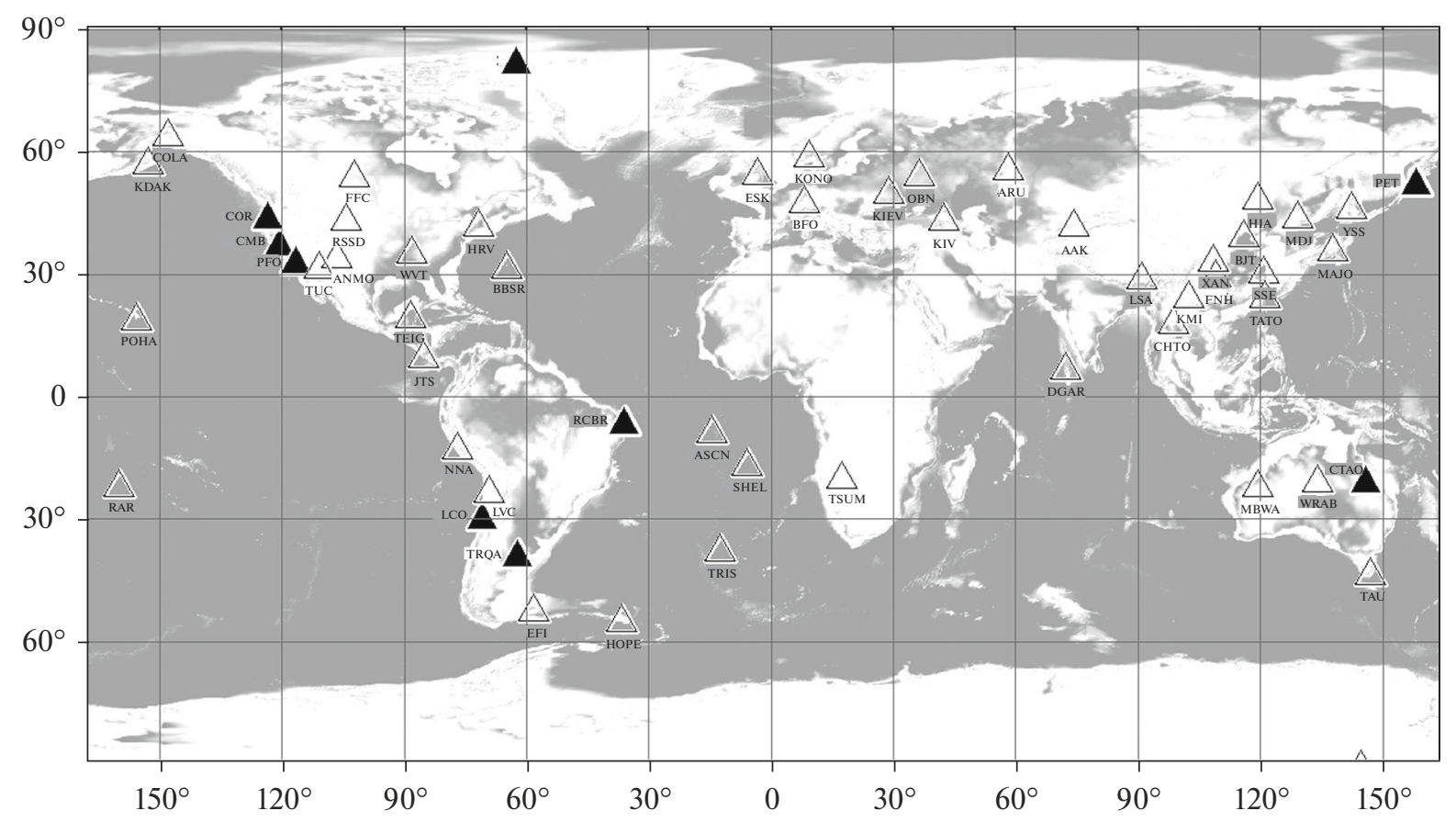

Fig. 1. The locations of the broadband seismic stations whose records are analyzed in this paper; those in black are stations where the coast effect has been detected.

theoretical tides. The comparison of the plots of dif and $\mathrm{P}$ shows that the amplitude of dif is independent of tide shape. Thus, it is possible to look for the effects of strain changes elsewhere. The analogy between the records of a seismic station and theoretical tides occasionally deteriorates. It is known, e.g., that the records of high altitude stations are affected by fluctuations of daytime and nighttime temperatures (Sobolev and Zakrzhevskaya, 2019). The domain of equal and maximum sensitivity of the STS-1 broadband seismograph lies in the range $0.2-360 \mathrm{~s}$. At longer periods, the sensitivity decreases by two orders of magnitude when the period is ten times as long. At periods $>10^{3}$ seconds a seismometer gradually becomes a gravimeter (Rykov, 1979). This is due to the action of the force of gravity on the pendulum spring. When the period is made still longer, the sensitivity varies little, and this allows a faithful reproduction of diurnal earth tide variations (see Figs. 2a, 2b).

Our information on strong magnetic storms was drawn from the archive http//www.spaceweatherlive.com. The tables in this archive give values of planetary $\mathrm{Kp}$-indices, which are deviations of the Earth's magnetic field from the normal values during threehour intervals in the respective 24-hour time spans (GFZ Potsdam official Kp-index). The values of the $\mathrm{Kp}$-indices lie in the range between 0 and 9 . When a magnetic storm happens to be very strong, the values $\mathrm{Kp}=9$ occur in several three-hour intervals. The archive lists 50 stronger magnetic storms for the period 1994-2017. They are arranged in the order of decreas- ing Ap-indices. The latter are found based on eight $\mathrm{Kp}$-indices for 24-hour intervals. They characterize the average daily planetary amplitude of disturbances in the Earth's magnetic field on a linear scale and are measured in nanoteslas (nT).

\section{RESULTS}

Consider, in Fig. 3, records of PFO [33.60 N116.45 W], COR [44.59 N-123.30 W], RSSD [44.12 N$104.04 \mathrm{~W}$ ], and HRV [42.51 N-71.56 W] during the October 29-31, 2003 storm. One can see that the interval of Kp-indices greater than 8, in the plots of the RSSD and HRV stations, contains high frequency spikes that are noticeable in the plots for COR and PFO. We have tested whether these differences stem from different structures of the magnetic storm at station sites. We used data on the intensity components of the magnetic field from INTERMAGNET Data over several geomagnetic observatories. Figure 4 shows records of the geomagnetic observatories FRN [37.09 N-119.72 W], NEW [48.27 N-117.12 W], and BOU [40.14 N105.24 W]. They are at distances of 134, 183, and $130 \mathrm{~km}$ from the PFO, COR, and RSSD seismic stations. We used the interval of 4 days between October 28 and 31, so that the first spikes in the plots correspond to the start of intensive oscillations, when the values of the $\mathrm{Kp}$-indices exceeded the value 8 . We note one peculiar feature in the records. The high frequency variations of the geomagnetic components are better seen at the NEW observatory near the COR seismic station com- 


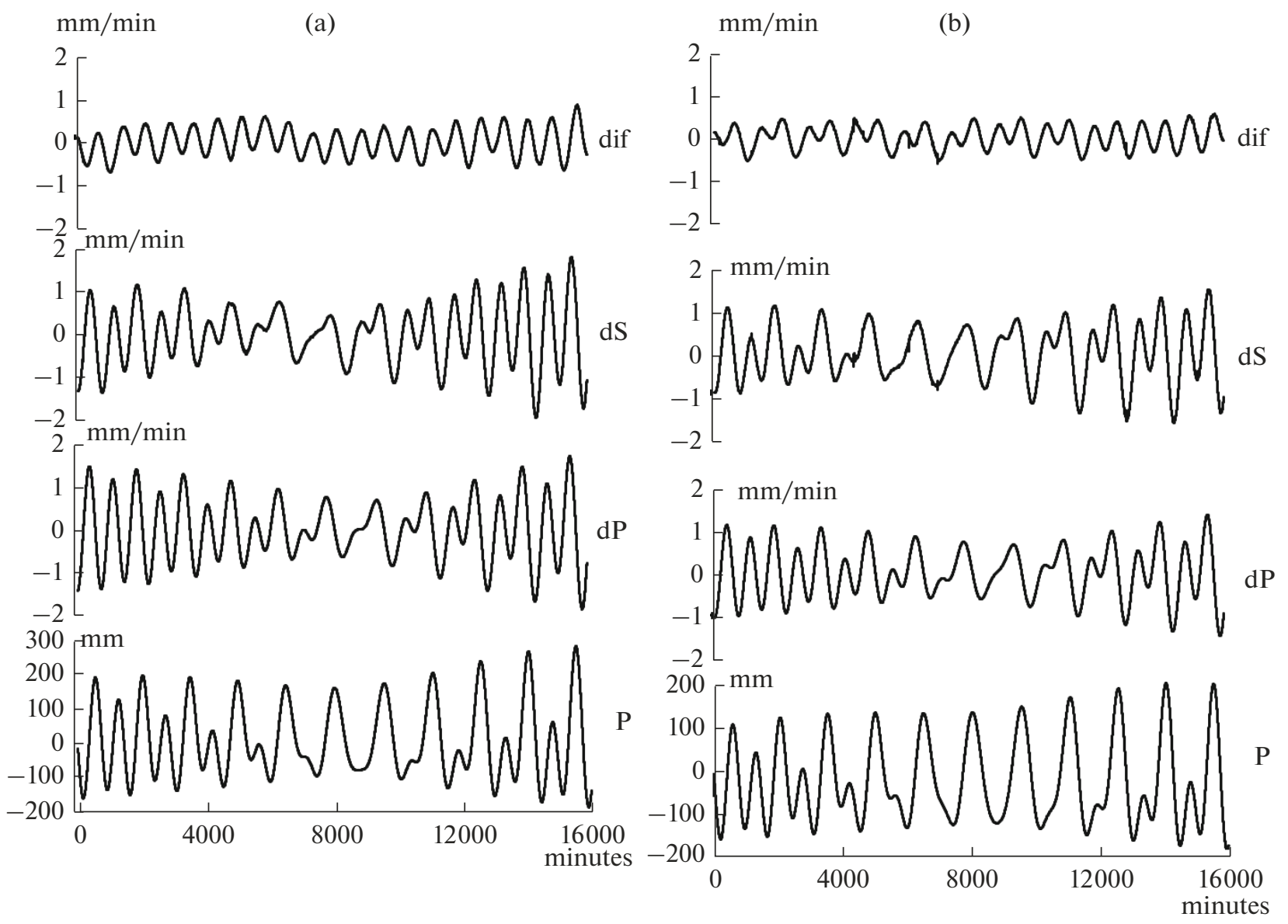

Fig. 2. The PFO (a) and COR (b) stations. $P$ is tide; $d P$ is the rate of tide change; $d S$ is the record of a seismic station; dif $=d S-d P$.

pared with the BOU observatory which is near the RSSD seismic station. At the same time, from Fig. 3 it follows that high frequency seismic oscillations were more distinct at RSSD, while being less noticeable at PFO and COR. Accordingly, the origin of these oscillations is not to be attributed to the magnetic field structure in the storm. The cause is probably to be sought in changes in the properties and water saturation of the rocks beneath the respective stations.

The seismic oscillations at periods of a few minutes due to magnetic storms were studied in a previous paper of ours based on a great number of broadband seismic stations (Sobolev et al., 2020b) where the following conclusions were drawn, among other things. Seismic pulses occurring during storms were observed on records of all stations in the continents, while being absent from stations installed on small islands in the middle of a deep ocean. The phenomenon was explained by the skin effect, viz., the attenuation of electromagnetic waves in highly conductive ocean water, thus providing evidence that the sources of the seismic pulses were in the solid earth. Our present study will not be concerned with variations at periods of a few minutes. We subdivided the raw observation series into two subranges using the Gauss filter of radius $90 \mathrm{~min}$. Spectral analysis showed that the range of higher frequencies clearly shows pulses with periods between 6 and $30 \mathrm{~min}$, while periods of 12 and 24 hours were more conspicuous in the low frequency range. The names of low frequency observation series will be complemented with figures 90 in what follows.

\section{Strain variations at periods of a few hours}

The times when large planetary Kp-indices $(>8)$ occur will be called here the beginning and end of a storm. Each $\mathrm{Kp}$-index was determined in a three-hour window, as mentioned above; they occupied the interval 4.2-6.8 days in Fig. 3. While not dwelling on the high frequency pulses (the RSSD and HRV stations), we note that there were no obvious changes (PFO and COR) during the beginning of the storm at periods of a few hours $(\mathrm{Kp}>8)$. We ask whether they can be detected by a formalized procedure. The strain rate $\mathrm{dS}$ describes changes in earth tide $\mathrm{dP}$ at high accuracy, which was pointed out in Figs. 2a, 2b. Suppose the regular process due to earth tide will be disturbed during a storm. We will try to find this out by calculat- 
THE INFLUENCE OF A MAGNETIC STORM ON TECTONIC DEFORMATIONS
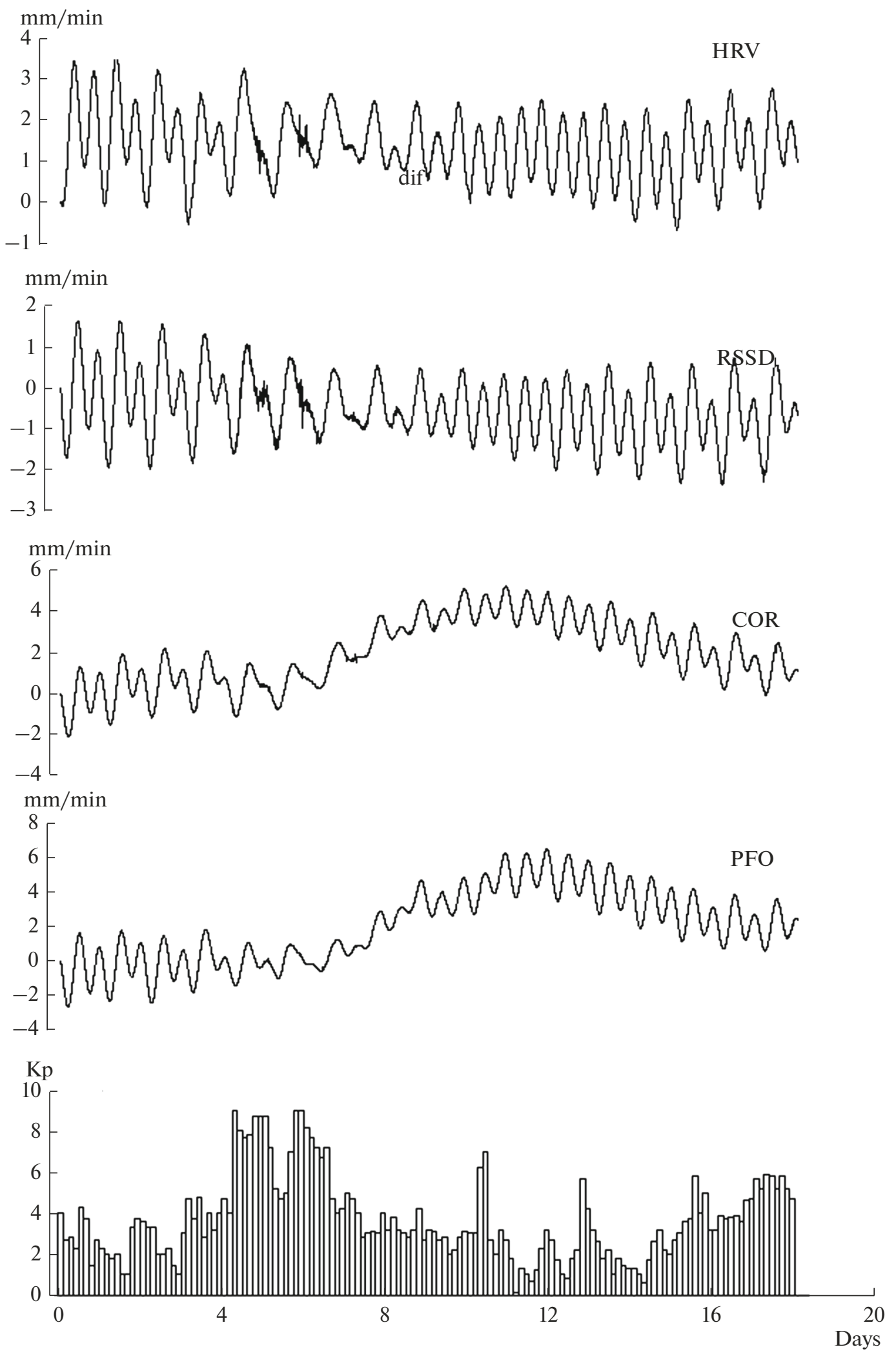

Fig. 3. Records of seismic stations installed near the continent-ocean boundary (PFO, COR) and of those far from it (RSSD, HRV) during the storm of October 29-31, 2003. Kp are planetary amplitudes of Kp-indices characterizing the intensity of a storm. 

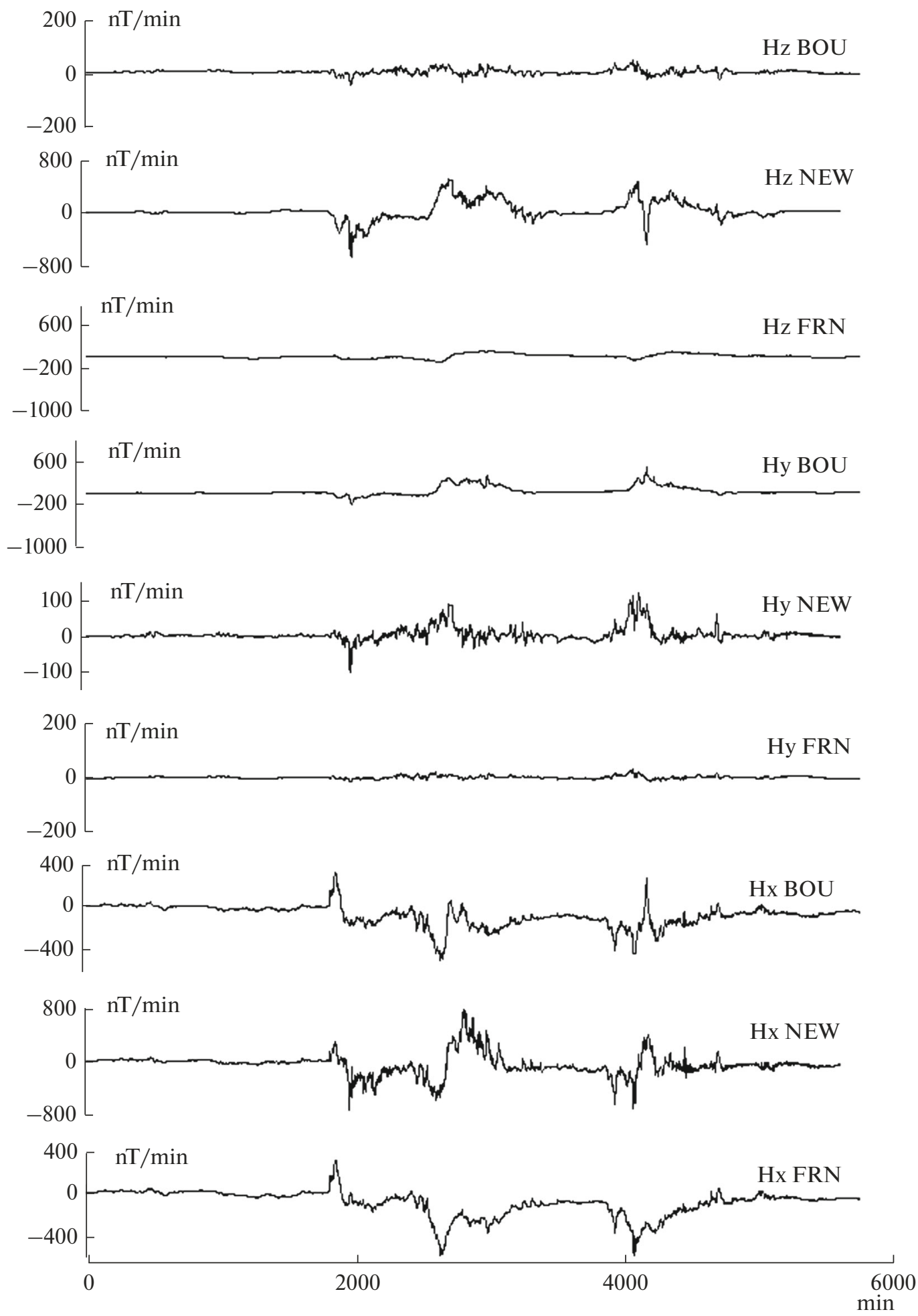

Fig. 4. Changes in components of magnetic field intensity during the storm of October 29-31, 2003 as recorded at the geomagnetic observatories FRN, NEW, BOU which are situated near the PFO, COR, and RSSD seismic stations.

ing a measure of coherency for different observational series. Coherency in physics is understood to be consistency between several oscillatory processes over time.
We will use A.A. Lyubushin's program WBRCM.exe, which the author kindly let us use (Lyubushin, 2007). A robust wavelet measure of coherency was found from 


$$
\kappa(\tau, \beta)=\prod_{k=1}^{q}\left|\bar{v}_{k}(\tau, \beta)\right|
$$

where $v_{k}(\tau, \beta)$ a coefficient that describes the strength of the connection between process no. $k$ to all the other processes; $\tau$ is the time coordinate of the right endpoint of the moving time window, $\beta$ is the level of detail attainable by calculating the coefficients $c_{j}^{(\beta, \tau)}(k)$ of the discrete orthogonal wavelet transform. The temporal "zone of responsibility" for the coefficient $c_{j}^{(\beta, \tau)}(k)$ is given by the power law $\Delta T=2^{\beta}$. We also calculated the lowest possible number of wavelet coefficients $\mathrm{L}_{\min }$ for the level of detail with number $\beta$, at which it is possible to calculate correlations. The values of the measure (1) can lie between 0 and 1 . The greater the value of $k(\tau, \beta)$, the stronger is the total connection between the processes under analysis. The value of the measure is a product $q$ of nonnegative quantities whose absolute values are below 1 . Of the greatest interest are, not the absolute values, but relative quantities for different $\tau$. For the results presented below, the number of wavelet coefficients was chosen to be $\mathrm{L}_{\min }=14$ to find Sym02 HAAR wavelets. More stable results were obtained by comparing differences between successive values in each sample.

We calculated the coherency measure using the following procedure. A record of a specified station was inspected to select three successive intervals shifted over time by $1440 \mathrm{~min}$ ( 24 hours), and to calculate $k(\tau$, $\beta$ ) by a joint analysis in a moving window at steps of $1 \mathrm{~min}$. It was supposed that the measure will have large values, if the process is described by periodic oscillations that repeat themselves during the three successive days ( 24 hours) due to earth tides. The influence of an extra source (a magnetic storm), which disturbs the tide process, must have reduced the coherency measure. Quantitative results from calculations of $k(\tau$, $\beta$ ) will be denoted coh (coherence).

This procedure was reasonable to use to detect changes in the strain process during a storm in those cases in which no gaps or manmade noise were present on records of the seismic stations. We shall discuss (Fig. 5) the results of this analysis for the time span October 22 to November 11, 2003 for the RSSD station installed in the middle of North America (see Fig. 1). Here and below, black curves show the rate of strain dS and the measure of coherency coh based on station data; the red curves present the results of analogous calculations based on theoretical tides. The initial values of the coh plots have been shifted by $4320 \mathrm{~min}$, which were expended to calculate $k(\tau, \beta)$ in the first of the three moving time windows. As a result, all plots were synchronized over time. The triangles mark the times of the beginning and end of the October 29-31 storm in the interval $\mathrm{Kp}>8$. It can be seen that, during the first 7 days $(\sim 10000 \mathrm{~min})$ before the storm, the coherency measure had values close to one, thus indi- cating a high degree of periodicity for the process. The measure began to decrease when the right endpoint of the moving three-day window reached the beginning of the storm. Afterwards, the coherence measure continued to decrease during four days, thus indicating a progressively greater mismatch of the process in successive intervals. A minimum of coh was recorded two days after the end of the storm (the second triangle). This result means that the storm induced changes in the rate of strain.

However, the rate of tide was changing during the storm, as is apparent from the plot of RSSDti (in red). This must naturally have affected the variation of coherence measure as calculated using the abovementioned WBRCM.exe program. The result of this calculation based on the tidal curve alone is shown in red at the plot of coh. The large difference in the amplitudes of coh (black and red curves) suggest the inference that the strain changes during the storm were not solely due to tidal shapes.

The results of analogous calculation for the COR station are shown in Fig. 6. The station is in the western North America at a distance of $1500 \mathrm{~km}$ from the RSSD station. As well as for the RSSD station, the anomalous lowering of coherence measure in strain rate is a few times that due to tidal shape alone. The next Fig. 7 demonstrates the variation in coherency in records of the RAR station installed on Raratonga Island in deeper Pacific Ocean. We can see smaller changes in coh amplitude during the magnetic storm. While the minimum amplitudes reached values of $0.7-0.8$ in the continent and in the region near the ocean (see Figs. 5, 6), the diminution at RAR was as small as 0.92. Sobolev et al. (2020a) found that seismic pulses at periods of a few hours were not detected on small islands in the ocean during magnetic storms. We can see now that the influence of a storm on the strain rate at periods of a few minutes on an island is lower than that on mainland. This might be related to the fact that electromagnetic oscillations are transformed into strain mostly beneath an island, while their energy is reduced due to the skin effect in conductive rocks in the surrounding layers beneath seafloor. Figure 8 presents changes in strain rate at stations installed in different locations over the world: SSE [31.095 N-121.186 E] (eastern China), CMB [38.035 N-120.386 W] (western US), and SNZO [41.310 S-174.705 E] (New Zealand). This effect of decreasing coherency measure is clearly seen, and does not depend on station location to a first approximation.

We wish to note some general properties of the phenomenon under discussion. In pre-storm intervals, all stations showed values of coh close to one, which reflected a stable periodicity in the process controlled by earth tides. The time when the coherence measure began to decrease was identical with the beginning of the magnetic storm to within approximately $\pm 2 \mathrm{~h}$. This scatter was due to the following fac- 


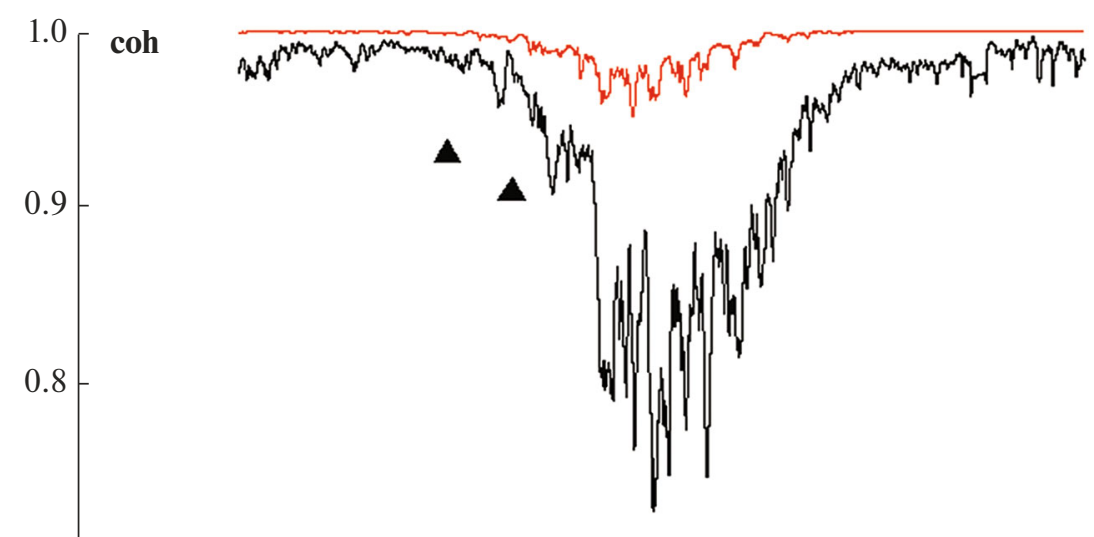

0.7
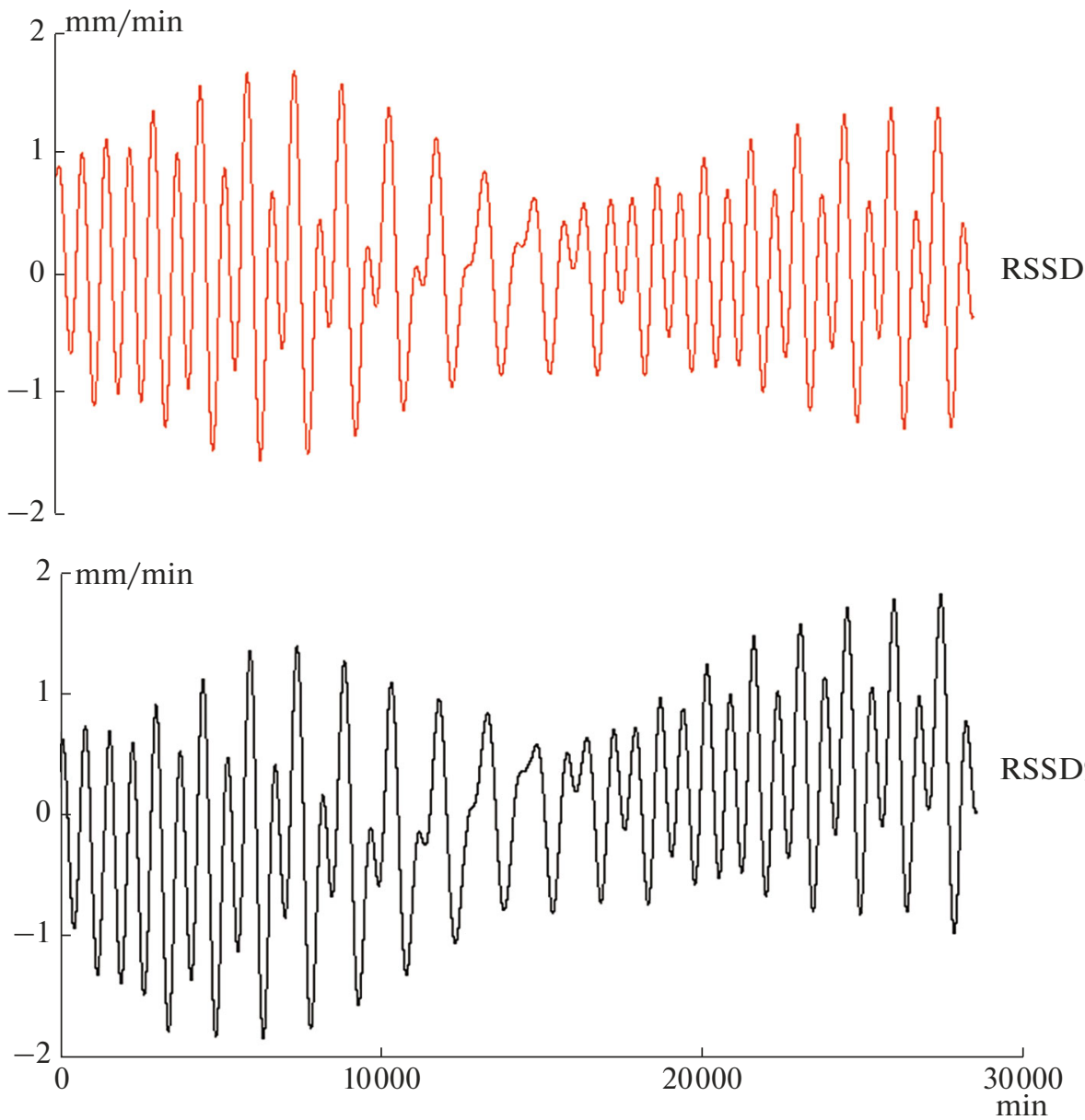

Fig. 5. A decrease in coherence measure coh during successive daily segments of a record made at RSSD during the storm of October 29-31, 2003 (in black). The red curves are results of analogous calculation based on tidal records. Triangles mark the start and end of the storm in the interval of $\mathrm{Kp}$-indices greater than 8.

tors: (a) the Kp-index is found as the mean in a threehour interval, (b) coh decreases gradually rather than in steps. If the minus sign in the estimated scatter has a physical meaning, then the coherence measure started decreasing prior to the magnetic storm. We note in this connection that Tarasov (2019) detected changes in seismicity before the variations in magnetic field intensity during magnetic storms. He thought it to be related to the sun's ionizing electromagnetic radiation due to a solar flare. The gradual decrease in coherence measure shown in Figs. 5-8 after a magnetic storm was evidently caused by the fact that changes in strain rate involved an increasingly longer interval in the moving three-hour window. The return 

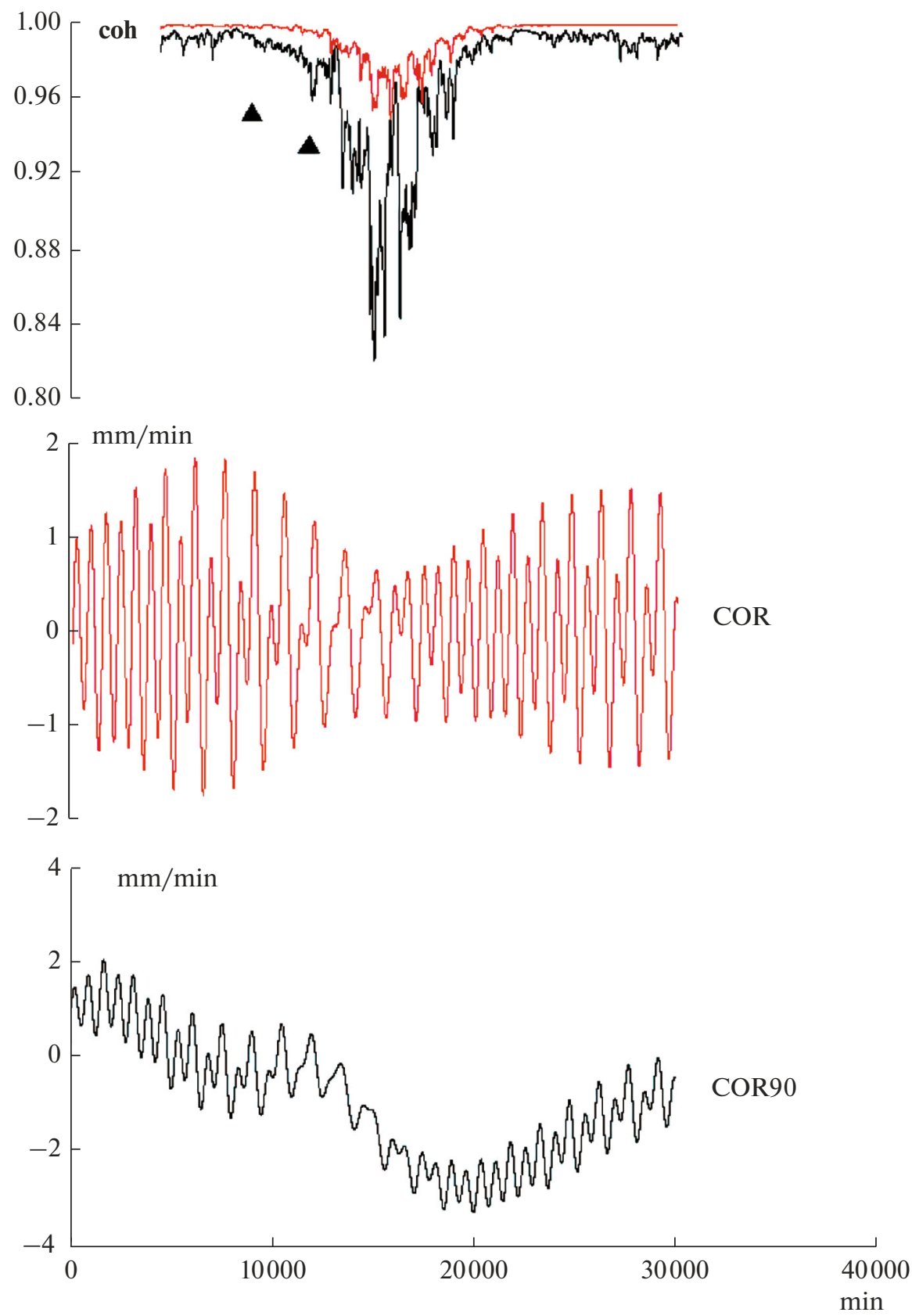

Fig. 6. A decrease in coherence measure coh in successive daily segments of a COR record during the storm of October 29-31, 2003 (in black). The red curves represent results of analogous calculation based on tidal records. Triangles mark the start and end of the storm in the interval of Kp-indices greater than 8.

to higher values provides evidence of a lesser effect of the storm on strain.

The results for all stations are roughly similar. At present we have only established the fact itself of strain changes. It is not clear what parameters change and what are their values. As an example, calculations of the lengths of the intervals between successive maxima and minima relative to the mean (1440 $\mathrm{min})$ showed that the differences do not go beyond the random data scatter. In this sense, the procedure we used to find coherence demonstrated an effective selective ability.
Summing up, we can safely assert that the storm gave rise to tectonic deformations in the one-hour range of periods in different regions worldwide. The geophysical cause hypothesized here consists in the appearance of an additional source other than the tides.

\section{The coast effect in tectonic deformations}

When we analyzed the rate of strain using data from 58 stations that were in full operation during the magnetic storm of October 29-31, 2003, some records 

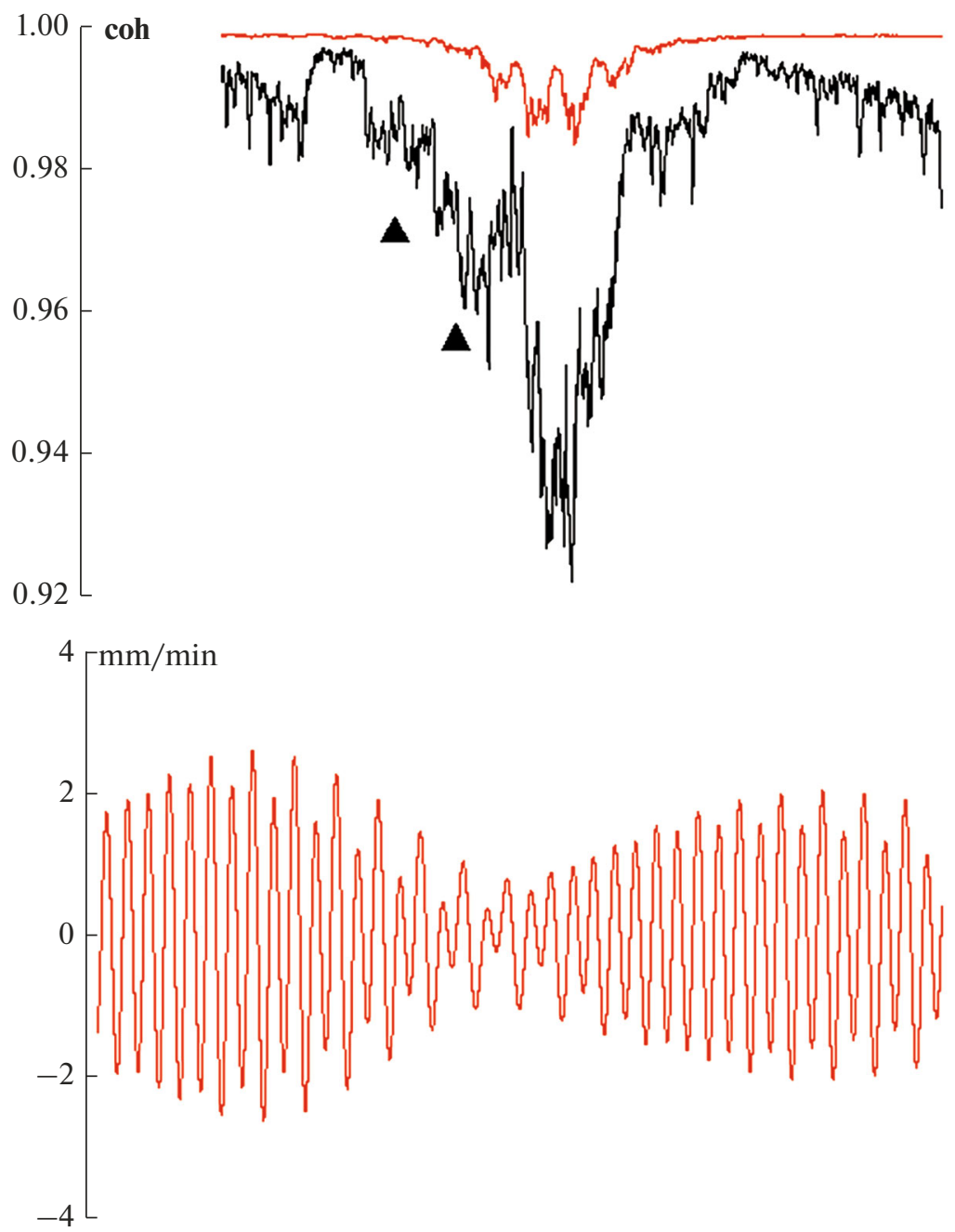

RAR

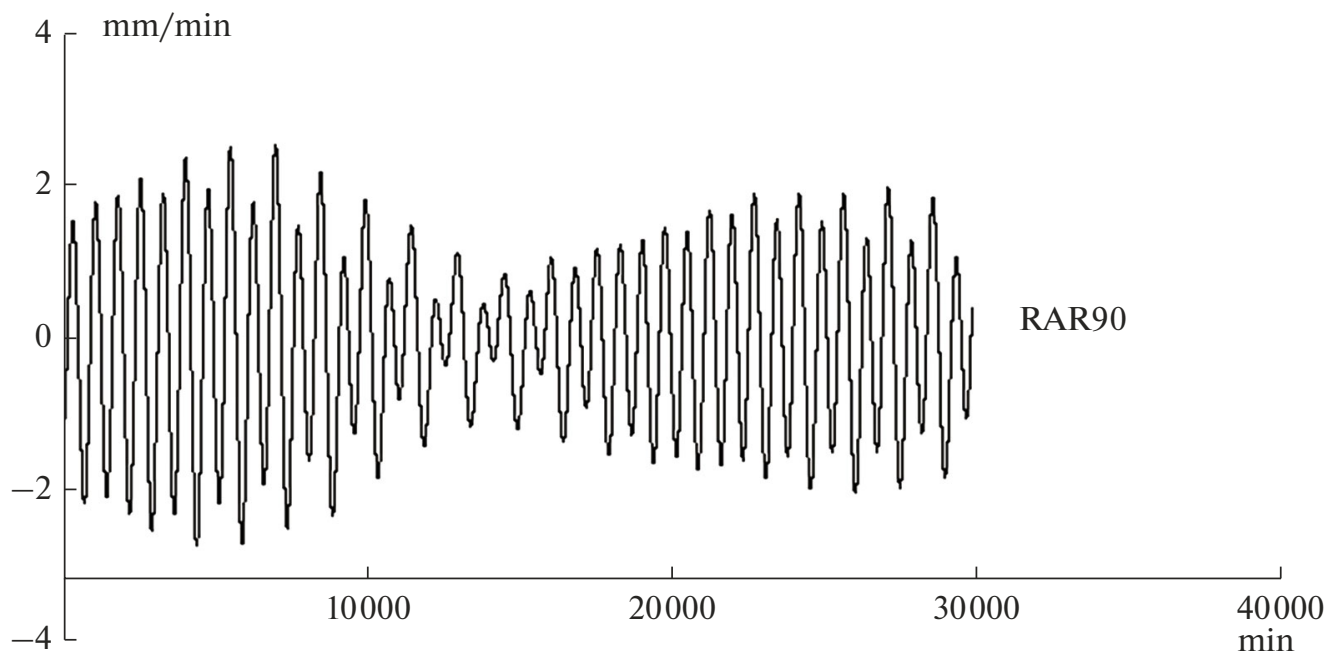

Fig. 7. A decrease in coherence measure coh in successive daily segments of a RAR record during the storm of October 29-31, 2003 (in black). The red curves represent results of analogous calculation based on tidal records. Triangles mark the start and end of the storm in the interval of $\mathrm{Kp}$-indices greater than 8. 

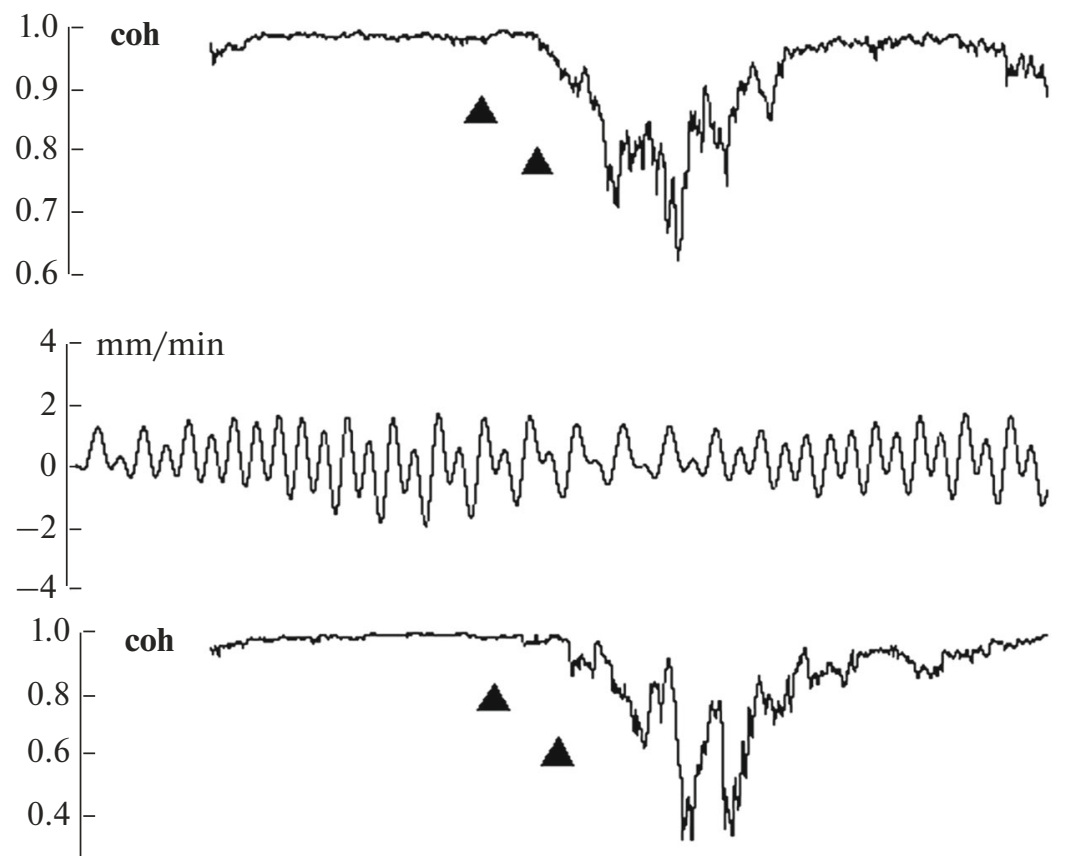

0.2

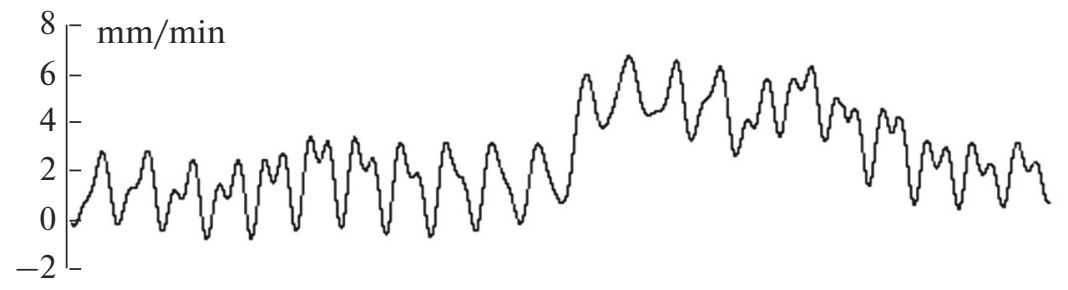

CMB90
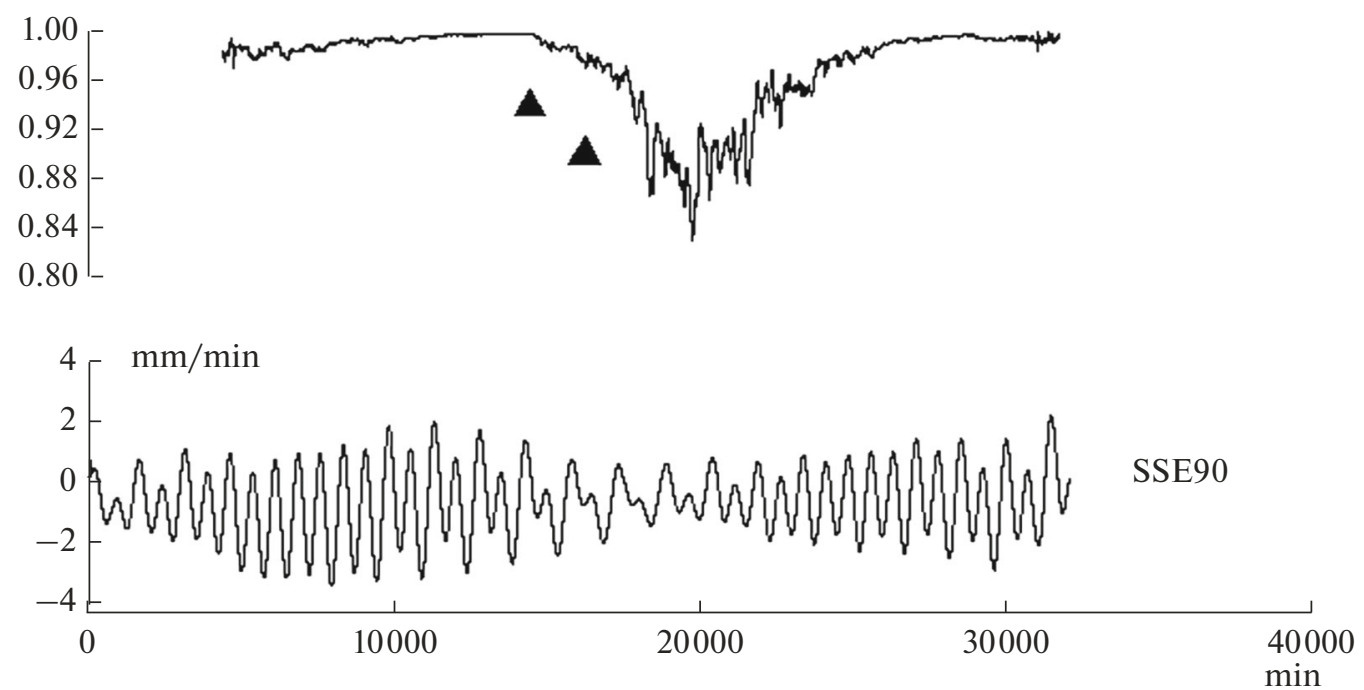

Fig. 8. A decrease in coherence measure coh in successive daily segments of records made at SSE, CMB, and SNZO during the storm of October 29-31, 2003. Triangles mark the start and end of the storm in the interval of Kp-indices greater than 8.

were found to contain post-storm changes in trend. We now return to Fig. 3 to compare post-storm records at stations nearer to the eastern coast of the Pacific Ocean (PFO, $100 \mathrm{~km}$ to the shore), COR $(96 \mathrm{~km})$ and at those farther away (RSSD, $1600 \mathrm{~km}$ and HRV, $4050 \mathrm{~km})$. An analogy in the evolution of the trend at the coastal stations (PFO and COR) and an absence of any changes at RSSD and HRV provide evidence of a significant role played by the oceancontinent boundary. 
We are going to compare (Fig. 9) records of the coastal stations which showed a change in the trend and the variations of other geophysical processes that may have influenced the effect. Plot 1 demonstrates the evolution of the October 29-31, 2003 storm as reflected in the level of Kp-indices. The structure of seismic oscillations dS is seen at North American stations (PFO and COR) and at PET, which is at about the same latitude in the eastern hemisphere (plots 2, 3, and 4). Above the plots are shown the coordinates and heights of these stations. They are in Pacific coastal regions. Both of the American stations, PFO and COR, showed a nearly synchronous increase in trend level after high values $(\mathrm{Kp}>8)$. The time that the trend increased until the subsequent drop was approximately 5 days. The distance between PFO and COR (see Fig. 1) is $1350 \mathrm{~km}$; the difference in height, $\mathrm{dH}=(1311-121 \mathrm{~m})$, is greater than $1 \mathrm{~km}$. We thus see that the trend variation occurred for over $1000 \mathrm{~km}$ along the eastern Pacific coast, and was unrelated to station heights. The trend variation was also observed at PET in the other hemisphere, although in a different manner. Considering the distance from the stations to the shore, the zone of trend penetration inland exceeded $100 \mathrm{~km}$.

The duration of trend variation at plots 2,3 , and 4 lies in the range of two-week fluctuations in earth tide. Accordingly, we used the PETGTAB software (Wenzel, 1999) to calculate the tides at the sites of the PFO, COR, and PET stations (plots 5, 6, and 7, red curves). We sought to compare the trends by first suppressing the semidiurnal and diurnal oscillations by the Gauss filter of radius 4320 values (three days). No significant pairwise correlation has been detected between the trends of strain rate $(2,3$, and 4$)$ and those of tides (5, 6 , and 7). Variations of weather conditions could be another factor to cause the changes in trend. We tested the hypothesis by finding hourly values of atmospheric pressure $P_{\text {atm }}$ based on data from weather stations closest to PFO, COR, and PET, namely, Palm Springs $\left[33.82^{\circ} \mathrm{N}, 116.55^{\circ} \mathrm{W}\right]$, Corvallis $\left[44.56^{\circ} \mathrm{N}\right.$, $123.28^{\circ} \mathrm{W}$ ], and Elizovskoe [53.15 $\left.\mathrm{N}, 158.45^{\circ} \mathrm{E}\right]$. In this case too, we have not detected a significant correlation between their structures (blue plots 8,9 , and 10 ) and hourly values of strain rate (plots 2,3 , and 4 ). One is thus compelled to admit that the "electromagnetic coast" effect (Parkinson, 1962; Moroz and Samoilova, 2017) must be reflected in the tectonic strain as recorded by the coastal seismic stations. We briefly discussed the effect in a previous publication (Sobolev, 2020a).

We will discuss this phenomenon (Fig. 10) over a longer time span of observation. We show records of three stations with no interruptions of operation or manmade noise prior to the October 29-31, 2003 storm. The plots in Fig. 10 span the interval from September 1 to November 11, 2003, and are values of dS at a step of one minute at the PFO, COR, and RSSD stations. The darker spots with higher amplitudes of semidiurnal and diurnal oscillations correspond with two-week cycles of earth tide. The variations lasting approximately 3 weeks as apparent in the COR records were probably due to local site conditions, and are not considered in the present study. The following features are important: (a) post-storm trend changes (triangles) are seen at PFO and COR, and (b) no such evident changes are present at RSSD. These facts are also consistent with the hypothesis that the coast effect has an impact on the strain as recorded by coastal stations.

Is the change in trend the property of a station equipped with an STS-1 seismometer? The PFO and ALE stations, which are in the coastal continentocean zone, also had seismometers of a different type (STS-2) operated simultaneously during the October 29-31, 2003 storm (Fig. 11). The highest sensitivity of the latter instrument is restricted to the periods less than or equal to $100 \mathrm{~s}$, but still they do record diurnal and semidiurnal oscillations. Plot 2 in Fig. 11 mimics plot 2 in Fig. 9 (STS-1), while plot 3 is from the STS2 seismometer. We see that the post-storm trend changes appear in records of both instruments. Plots 4 and 5 in Fig. 11 are from the ALE station [82.50 N $62.558 \mathrm{~W}]$ situated on the coast of the Arctic Ocean (see Fig. 1). The post-storm disturbances in the trend are also seen on records of both instruments. Sharper post-storm changes in trend at ALE compared with PFO seem to have been due to a greater storm intensity near ALE. The INTERMAGNET data tell us that the magnetic field intensity at the high-latitude THL Observatory [77.47 N-69.29 W] near ALE was 5 times that at the FRN Observatory [37.09 N-119.72 W] near PFO during the storm. The spikes of the horizontal components $\mathbf{H x}$, which have the greater intensity, were characterized by values of $2000 \mathrm{nT}$ and $400 \mathrm{nT}$.

A study of records of other stations installed near the continent-ocean boundary showed that the structure, amplitude, and polarity of post-storm trend variations were different at different stations. The coast effect of varying shape and amplitude was detected in records of the following stations: COR (western US), PFO (western US), ALE (northeastern Canada), CMB (western US), CTAO (northeastern Australia), LCO (western South America), TRQA (western South America), and RCBR (eastern South America). An analysis of records (without gaps or noise) at coastal stations SSE (eastern China) and NNA (western South America) has not detected the effect.

It has not been possible to study a large number of coastal stations owing to gaps in raw one-second data. The impression is that the coast effect is best seen in relatively straight long coastal continent-ocean strips. The region where the effect was observed in the western North America extended for more than $1000 \mathrm{~km}$ in the north-south direction.

Changes in the strain recorded at stations, and manifestations of the coast effect, were also detected for other storms. One serious restriction consisted in our requirement of no gaps or failures in one-second 

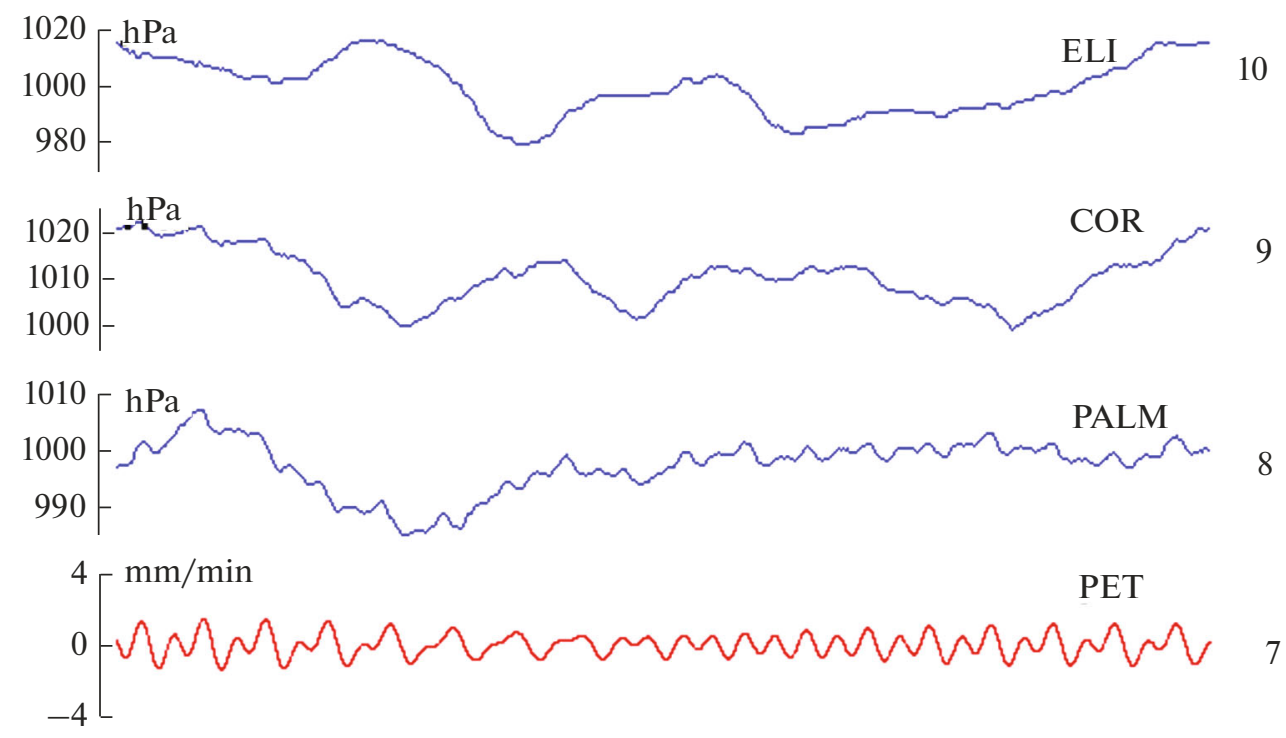

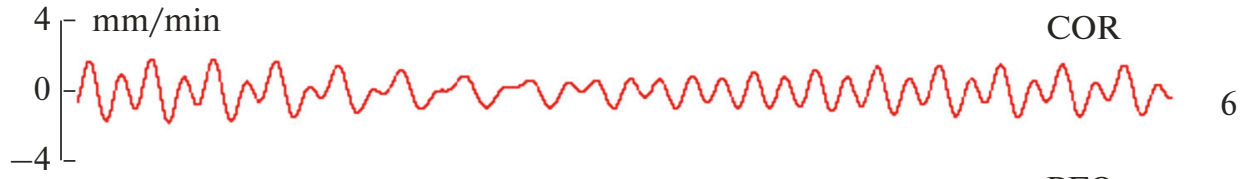

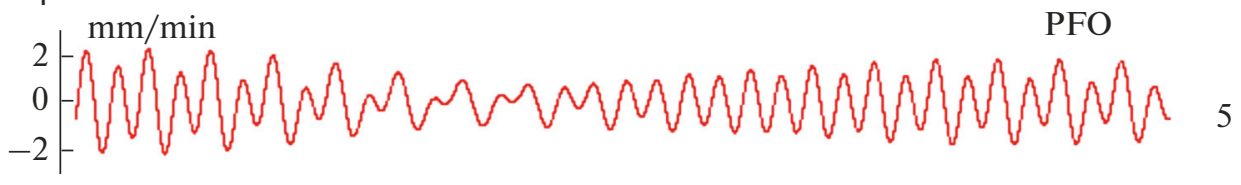
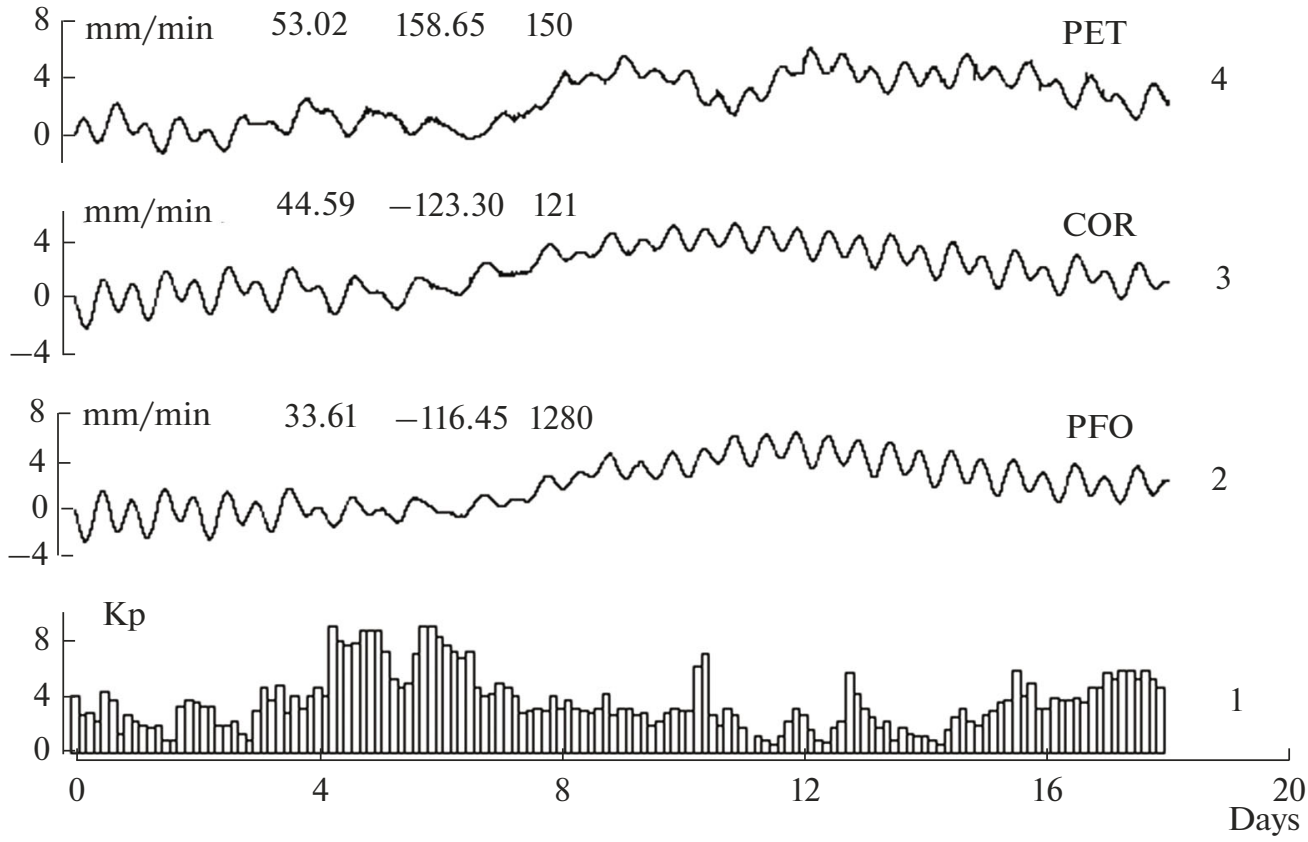

Fig. 9. Variations in several geophysical parameters during the magnetic storm of October 29-31, 2003. (1) Kp is storm intensity; the variations (2-4) are strain rates and (5-7) are rates of earth tide at the PFO, COR, and PET seismic stations; (8-10) changes in atmospheric pressure at weather stations closest to these (PALM, COR, and ELI).

records based on durations of many days, thus ruling out any approximation. One example is shown in Fig. 12 where the same COR station was continuously operated during the storm of July 27, 2004; results from the station were used for the October 29-31, 2003 storm. The effects of distortions in strain rate and trend changes were observed in both of these cases. There are differences too. The coherence measure coh began 

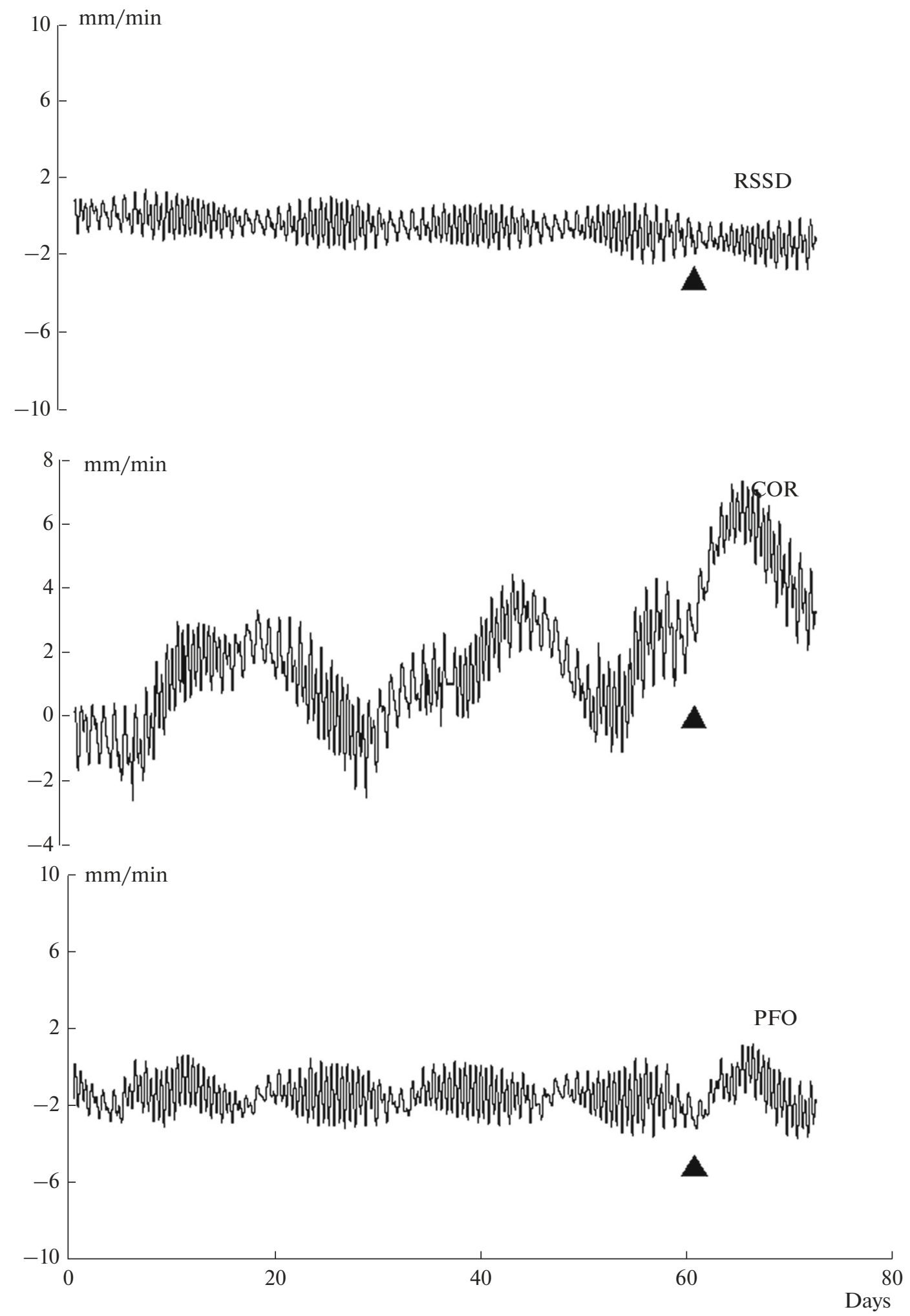

Fig. 10. Long-term changes in strain rate dS at the PFO, COR, and RSSD stations before and after the October 29-31, 2003. The triangle marks the start of the storm. 

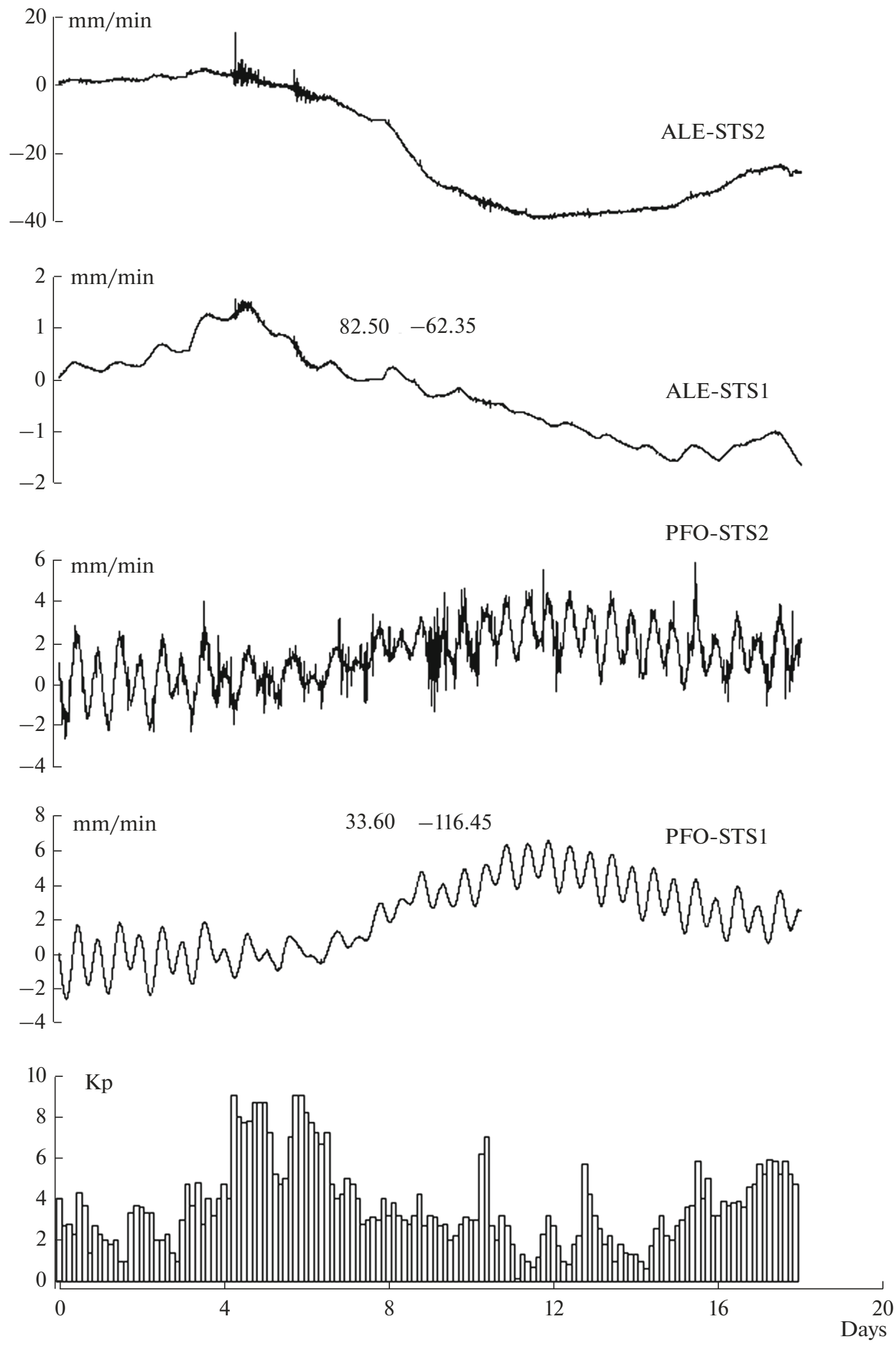

Fig. 11. The occurrences of trends after the October 27-31, 2003 at the PFO and ALE stations by STS-1 and STS-2 seismographs. Station coordinates are indicated above the plots; the minus sign means west longitude. Kp denotes storm intensity. 

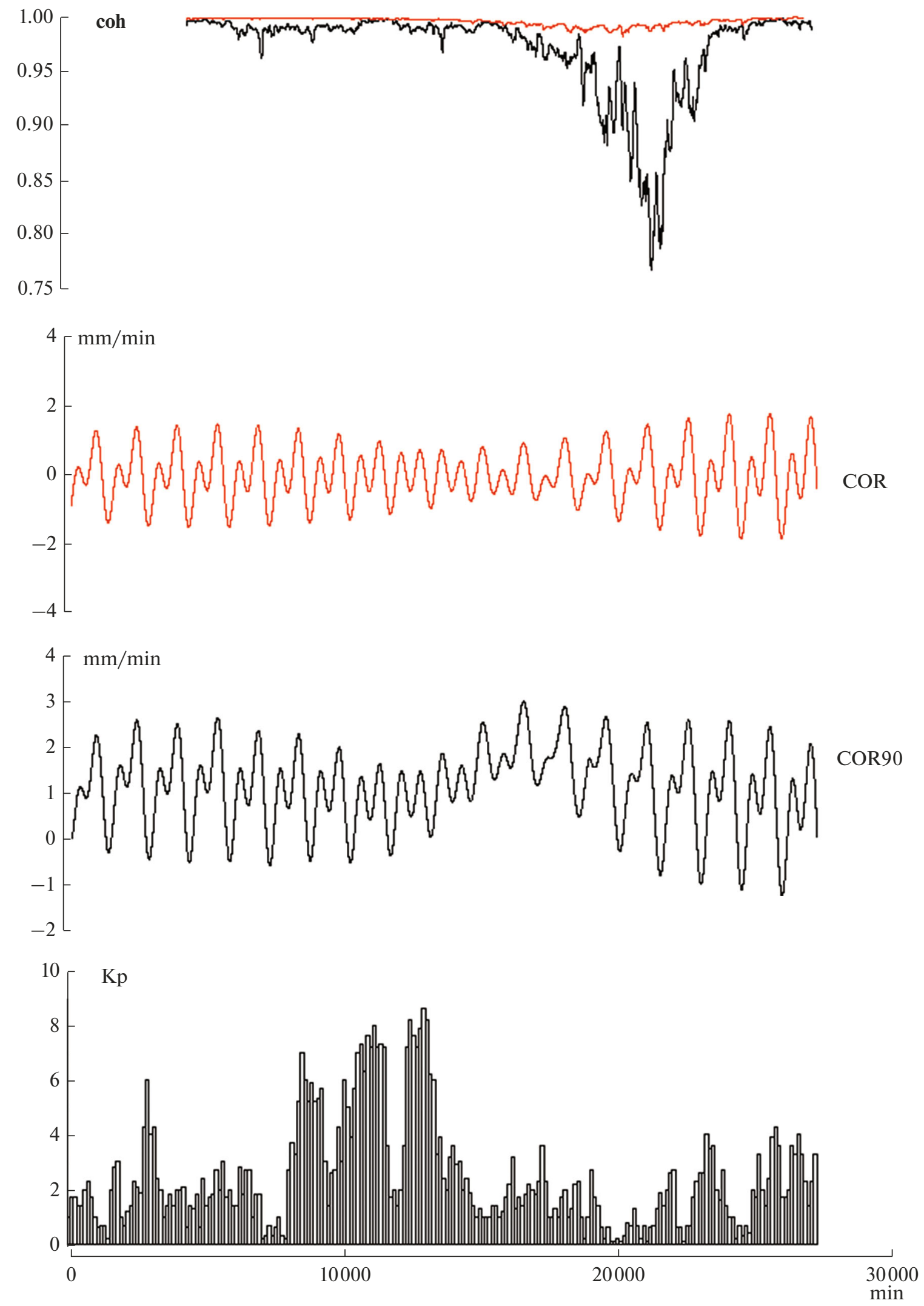

Fig. 12. A decrease in coherence measure coh in successive daily segments of a COR record during the storm of July 27,2004 (in black). The red curves represent results of analogous calculation based on tidal records. Kp denotes storm intensity. 
to decrease later than the maximum values of $\mathrm{Kp}$ indices during the July 27, 2004 storm, and the risedecrease duration in the trend was shorter. This seems to have been due to the following factors: (a) the July 27, 2004 storm had a lower intensity $(\mathrm{Kp}=8.6, \mathrm{Ap}=186)$ compared with that of October 29-31, $2003(\mathrm{Kp}=9$, $\mathrm{Ap}=204)$; (b) it started from a gradual increase in Kpindices (from 7 to 8.6), while the storm of October 2931,2003 started from the maximum value, $\mathrm{Kp}=9$.

\section{CONCLUSIONS}

Comparison of the coherence measure coh for different record segments to strain rate dS based on data of broadband seismic stations shows that coh decreased during a magnetic storm compared with the pre-storm background. The pre-storm coh values were close to 1 , which is a reflection of the stability of the process. The time when the coherence measure started decreasing was to a first approximation coincident with the appearance of high amplitudes of the Kpindices $(>8)$ which characterize the violence of a storm. The interval of low coh values lasted a few days. This effect of distortions in quasi-periodic strain controlled by earth tides seems to provide evidence of the action of a source other than the tide during the storm.

There were cases reported in the literature when magnetic storms affected earthquakes and seismic noise. The conversion sources in the solid Earth were hypothesized to be piezoelectrical, seismoelectrical, and tectonomagnetic effects, and phenomena of electrical polarization, among others. The results presented in this paper provide arguments in favor of water as the chief agent. Strain changes during storms were recorded at different stations at about the same level, in spite of differences in substation geology. As an example, the PFO, COR, and RSSD stations stand on marine sandstone, volcanogenic rocks, and limestone, respectively.

Electric current induces motion in water, which enhances the coast effect. This is based on the geomagnetic coast effect which was studied in multiple works (Marderfeld, 1977; Berdichevsky et al., 1992; Moroz and Samoilova, 2017). The effect involves concentration of electrical currents in the coastal zone between a high-conductivity medium (ocean) and a low-conductivity medium (mainland). Consequently, the amplitude of telluric currents increases on land near the shore. Judging from estimated conductivity for various lithosphere layers using the method of magnetotelluric sounding, the influence of the geomagnetic coast effect extends down to a few kilometers depth.

Electrokinetic phenomena play the key role in the mechanism whereby the electric field is transformed into strain. Larger currents lead to changes in the rate of percolation for the liquid due to electro-osmosis. Laboratory experiments showed that the rate of perco- lation is directly proportional to the increase in current (Sobolev et al., 2020a). Higher rate of percolation gives rise to several phenomena that have direct bearing on the variation of tectonic deformation. The origin of these phenomena differs according to the degree of saturation with deep fluids whose concentration in the lithosphere experiences substantial changes (Rodkin and Rundkvist, 2017). When a rock saturated with a liquid is under inhomogeneous compression, the pore pressure may increase. This affects the effective tectonic stresses in accordance with the modified Coulomb-Mohr law, hence can produce microfailure. The filling of pores in a relatively dry rock leads to density changes. The diversity, values, and patterns of different mechanisms were discussed in a study of interaction between geophysical fields (Adushkin and Spivak, 2019) and in a laboratory study (Smirnov et al., 2020).

It is poorly known how the above mechanisms influenced the formation of the coast effect in tectonic deformations. That is evidently dependent on the composition and properties of lithosphere rocks. As well, the magnitudes of the strain changes described above cannot be assessed accurately, because we do not know the sensitivity of the broadband seismometer at periods of a few days. However, it follows from Figs. $3,8,10$, among others, that the changes in strain rate before and after a storm are of the same order as earth tide variations. The latter have values of $\sim 2 \mathrm{~mm} / \mathrm{min}$, when earth tide variations are $400 \mathrm{~mm}(200 \mu \mathrm{Gals})$ (Melchior, 1966). The recorded variations in tectonic deformation of this magnitude can be explained by a change in the porosity of a rock with density $3.5 \mathrm{~g} / \mathrm{cm}^{3}$ beneath a station amounting to a mere $10^{-3} \%$ in a layer $1 \mathrm{~km}$ thick. We note that the gravity changes due to the coast effect could have been measured by an absolute gravimeter installed at the shoreline.

\section{CONCLUSIONS}

Changes in tectonic deformation due to earth tides have been detected during a storm.

We have detected the coast effect in tectonic deformation as post-storm changes in deformation in lithospheric regions adjacent to the ocean.

\section{FUNDING}

This work was supported by the Russian Foundation for Basic Research, project no. 18-05-00026.

\section{OPEN ACCESS}

This article is licensed under a Creative Commons Attribution 4.0 International License, which permits use, sharing, adaptation, distribution and reproduction in any medium or format, as long as you give appropriate credit to the original author(s) and the source, provide a link to the Creative Commons licence, and indicate if changes 
were made. The images or other third party material in this article are included in the article's Creative Commons licence, unless indicated otherwise in a credit line to the material. If material is not included in the article's Creative Commons licence and your intended use is not permitted by statutory regulation or exceeds the permitted use, you will need to obtain permission directly from the copyright holder. To view a copy of this licence, visit http://creativecommons.org/licenses/by/4.0/.

\section{REFERENCES}

Adushkin, V.V. and Spivak, A.A., Problems related to the interaction of geospheres and physical fields in nearsurface geophysics, Izv., Phys. Solid Earth, 2019, vol. 55, pp. 1-11.

Barsukov, O.M., Solar flares, sudden commencements, and earthquakes, Fizika Zemli, 1991, no. 12, pp. 93-97.

Hardle, W., Applied Nonparametric Regression, Cambridge, N. Y., New Rochell, Melbourne, Sydney: Cambridge University Press, 1989.

Berdichevsky, M.N., Koldaev, D.S., and Yakovlev, A.G., Magnetotelluric sounding on oceanic coast, Fizika Zemli, 1992, no. 6, pp. 87-96.

Jeffrey, J.L. and Jeremy, N. Thomas, Insignificant solarterrestrial triggering of earthquakes, GRL, 2013, vol. 40, pp. $1165-1170$. https://doi.org/10.1002/grl.50211

Lyubushin, A.A., Analiz dannykh sistem geofizicheskogo $i$ ekologicheskogo monitoringa (The Analysis of Data Coming from Systems of Geophysical and Ecological Monitoring), Moscow: Nauka, 2007.

Malinin, N.N., Prikladnaya teoriya plastichnosti i polzuches$t i$ (An Applied Theory of Plasticity and Creep), Moscow: Mashinostroenie, 1975.

Marderfeld, B.E., Beregovoi effekt $v$ geomagnitnykh variatsiyakh (The Coast Effect in Geomagnetic Variations), Moscow: Nauka, 1977.

Melchior, P., The Earth Tides, Pergamon Press, 1966.

Moroz, Yu.F. and Samoilova, O.M., The regional and coast effects in the magnetotelluric field of Kamchatka, Geofiz. Issled., 2017, vol. 18, no. 3, pp. 81-94.

Parkinson, W.D., The influence of continents and oceans on geomagnetic variations, Geophys. J. Roy. Astr. Soc., 1962, vol. 6, pp. 441-449.

Rodkin, M.V. and Rundkvist, D.V., Geoflyudogeodinamika (Geofluidgeodynamics), Dolgoprudnyi: Intellekt, 2017.
Rykov, A.V., On observations of the Earth's oscillations. Instrumentation, methods, and results, Seismich. Instrum., no. 12, Moscow: Nauka, 1979, pp. 3-8.

Smirnov, V.B., Ponomarev, A.V., Isaeva, A.V., et al., Fluid initiation of fracture in dry and water saturated rocks, Izv., Phys. Solid Earth, 2020, vol. 56, pp. 808826.

Sobolev, G.A., The coast effect of tectonic deformations due to magnetic storms, Dokl. Akad. Nauk, 2020, vol. 495, no. 11 , pp. 47-51.

Sobolev, G.A. and Zakrzhevskaya, N.A., Spatial and temporal structure of global low-frequency seismic noise, Izv., Phys. Solid Earth, 2019, vol. 55, pp. 529547.

Sobolev, G.A. and Zakrzhevskaya, N.A., Local tectonic deformations and nearby contemporaneous earthquakes, J. Volcanol. Seismol., 2020, vol. 14, no. 3, pp. 137-144.

Sobolev, G.A., Zakrzhevskaya, N.A., and Kharin, E.P., On the relationship between seismicity and magnetic storms, Fizika Zemli, 2001, no. 11, pp. 62-72.

Sobolev, G.A., Ponomarev, A.V., Kireenkova, S.M., and Maibuk, Z-Yu.Ya., An experimental study of the effects of direct electrical currents on the filtering of suspensions in a rock, Geofiz. Issled., 2020a, vol. 21, no. 3, pp. 19-33.

Sobolev, G.A., Zakrzhevskaya, N.A., Migunov, I.N., et al., Effect of magnetic storms on low-frequency seismic noise, Izv., Phys. Solid Earth, 2020b, vol. 56, pp. 291-315.

Tarasov, N.T., The influence of solar activity on terrestrial seismicity, Inzhen. Fizika, 2019, no. 6, pp. 23-33.

Trenkin, A.A., A possible influence of telluric currents on crustal seismicity in seismic regions, Geomagn. Aeron., 2015, vol. 55, no. 1, pp. 139-144.

Wenzel, G., Program PETGTAB. Version 3.01, Hannover: Universität, 1999.

Wieland, E. and Streckeisen, G., The leaf-spring seismometer-design and performance, Bull. Seismol. Soc. Amer., 1982, vol. 72, pp. 2349-2367.

Yesugey, S.C., Comparative evaluation of the influencing effects of geomagnetic storms on earthquakes in the Anatolian Peninsula, Earth Sci. Res. J., 2009, vol. 13, pp. 82-89.

Zakrzhevskaya, N.A. and Sobolev, G.A., The influence of magnetic storms with sudden commencements on seismicity in several regions, Vulkanol. Seismol., 2004, no. 3, pp. 63-75.

Translated by A. Petrosyan 